\title{
A Five-Year Retrospective Study of Small Ruminant Cases Presented to the State Veterinary Hospital, Ibadan Nigeria
}

\author{
Wahab Y. A ${ }^{1 *}$, Akinlabi E. Y², Raheem K. A ${ }^{3}$ \\ ${ }^{1}$ Department of Veterinary Medicine, University of Ibadan, Ibadan, Nigeria. \\ ${ }^{2}$ Department of Animal Health and Production Technology, Rufus Giwa Polytechnic, Owo, Ondo State, Nigeria. \\ ${ }^{3}$ Department of Theriogenology, Michael Okpara University of Agriculture, Umudike, Nigeria. \\ *Corresponding author: wahabyunus.abiola@gmail.com
}

\begin{abstract}
A five-year retrospective study was conducted using clinical case record of sheep and goat presented for treatment at State Veterinary Hospital, Ibadan, Nigeria between July 2013 and June 2018. A total of 520 small ruminants were presented within this period.Simple descriptive frequency statistic was employed to determine disease prevalence. Out of the 520 small ruminants presented, 360(69.2\%) were sheep and $160(30.8 \%)$ were goat. The most frequently diagnosed diseases in these animals were endoparasitism (31.3\%), viral infections (18.3\%), bacterial infections (15.6\%), reproductive conditions $(8.3 \%)$ and musculoskeletal disorders (7.7\%). Prevalence of diseases among small ruminants revealed that endoparasitism (22.5\%), viral infections (12.3\%), bacterial infections (10.2\%), musculoskeletal disorders (6.3\%) and reproductive conditions $(5.2 \%)$ were the most prevalent in sheep while endoparasitism (8.8\%), viral infections (5.96\%), bacterial infections (5.4\%) and reproductive conditions(3.1\%) were most prevalent in goats. The study has shown that endoparasitism, viral infections, bacterial infections and reproductive conditions are the leading problem ravaging small ruminants. Therefore, there is need for urgent intervention with special interest towards ensuring proper animal management to control the effect of these agents. It is recommended that livestock farmers should adopt best management practices that will minimize the vulnerability of small ruminants to disease. More so, there should be mass vaccination campaign against preventable diseases like PPR.
\end{abstract}

Keywords - Disease, goat, prevalence, retrospective study, sheep.

\section{INTRODUCTION}

Livestock sectoris one of the major contributors to the overall gross domestic product of most developing nation. It enhances the living of most livestock farmers as it help to generate steady incomes (Ajala et al., 2008). Livestockespecially sheep and goat are very importantto the rural dwellers who rely solely on the turnover from this animals. They are widely distributed in the rural, urban and peri-urban region (Ajala et al., 2008). To a very large extent, they serve as source of employment to an appreciable number of people, such as animal herders, feed millers, butchers, thereby generating wealth and as such contribute to the economy of the nation (Ogbaje et al., 2012). Sheep and goat are very valuable for social function as they are used to fulfil cultural rites during wedding, naming and burial ceremony. Sheep is particularly used during religious festivities, as such they are often regarded as more valuable than goat (Aliyu et al., 2005). Undoubtedly, the contribution of small ruminants to the overall daily protein consumption cannot be underestimated. They serve to augment beef which is the major source of meat for Nigerians (Ajala et al., 2008).However, the small size of the animals and high market price of their meats makes the animals less demanded for regular meat consumption (LawalAdebowale, 2012). Nonetheless, little resources is required for purchasing stock animal, land, feed and other necessary requirements needed to start up the production coupled with relatively little risk and tendency to multiply owing to their reproductive efficiency (Omoike, 2006).This makes it more affordable for average poor livestock farmers which contribute larger percentage of the livestock keepers. However, these animals are poorly managed as they are allowed to roam freely on extensive and semiintensive system. With this system of rearing, the animals are not properly monitored, most often they are faced with malnutrition, exposed to the adversity of extreme weather conditions with little or no access to veterinary care, making them so vulnerable to incidence of various diseases(Lawal-Adebowale,2012). 
Diseases remain one of the major threats to the livestock industry. Livestock animals are constantly being threatened by various livestock diseases which in turn affect their optimal productivity (MacRae et al.,2005). This is as a result of its negative effect through morbidities, mortalities and abortions or through, quality and the cost of time and money in management of the diseases (Singh \& Prasad, 2008).

Despite this worrisome impact on the economy, high prevalence of livestock diseases has often been reported in developing countries like Nigeria, they are mostly caused by microorganism such as bacteria, viruses, parasites, mycoplasma, ricketsia, protozoan and nutritional or managemental factors (Abiola et al., 2016).For instance, parasitism has been reportedas one of the major agents causing serious problem in ruminant in developing countries especially where nutrition and sanitation are poor Odoi et al., (2008), affecting health of millions of animals causing huge economic loss to livestock farmers (Ahmed et al., 2010). Retrospective study of animal diseases is a rapid and cheap means to identify the strategy for effective disease control when analyzed statistically(Abiola et al., 2016).This underscores the significant of this retrospective study of clinical diseases diagnosed at the State Veterinary Hospital, Ibadan, Nigeria. We envisioned that the data generated would give us the recent picture of pattern of disease occurrence which will be useful for epidemiological surveillance and to formulate policies towards proper intervention for disease control.

\section{MATERIALS AND METHODS}

\section{Study Area}

The study was conducted in Ibadan, the capital city of Oyo State, South-western region of Nigeria. The city lies at latitude $7^{\circ} 23^{\prime} \mathrm{N}$ and Longitude $3^{\circ} 56^{\prime} \mathrm{E}$ and it is located at the transition zone between the forest and grassland areas of the country. The state veterinary hospital is the only state government owned veterinary hospital centrally located at Mokola area of the cityand it serve as one of the major veterinary hospital affordable to small scale livestock farmers.

\section{Methodology}

This five years retrospective study was conducted based on the clinical record of sheep and goat presented to the State Veterinary Hospital, Ibadan between July 2013 and June 2018. The first part of the clinical case record contains information about the patient and the owner and the second part captures the history relating to the case presented, clinical signs observed, clinical parameter recorded, laboratory investigation conducted, disease diagnosed and treatment instituted. Diagnoses were often made based on history, clinical signs presented and laboratory analysis.

\section{Statistical analysis}

Data gathered were analysed based on species and disease conditions using simple descriptive statistic.

\section{RESULTS}

The result of this retrospective study revealed that overall 520 small ruminant cases were presented to the State Veterinary Hospital, Ibadan Nigeria between July 2013 and June 2018. Out of which, 260(69.2\%) of the animal presented were sheep and $160(30.8 \%)$ were goats (Table 1).

Common clinical conditions diagnosed were classified according to Abiola et al., (2016); bacterial infection (septicaemia, pasteurellosis, foot rot, tetanus), viral infection (Peste de Petit ruminante PPR, Orf, sheep pox), endoparasitism (helminthosis, haemoparasitism and verminous pneumonia), ectoparasitism (mange, tick, fleas and lice infestation), reproductive conditions (dystocia, placenta retention, uterine prolapse, vaginal prolapse, abortion, pyometra, metritis, vulvitis and mastitis), gastrointestinal conditions (bloat, ruminal impaction and rectal prolapse), musculoskeletal disorders (fracture, arthritis and trauma), respiratory conditions (pneumonia) and other conditions (poisoning, snake bite, malnutrition, conjunctivitis, dog bite, hernia, wound, keratitis, toxicosis and minerals deficiency).

Of the 360 cases of sheep diagnosed, endoparasitism was found to be most prevalent $117(32.5 \%)$ followed by viral infections 64(17.8\%), bacterial infections 53(14.7\%), musculoskeletal disorders $33(9.2 \%)$, reproductive conditions 27(7.5\%), other conditions 24(6.7\%), ectoparasitism $17(4.72 \%)$, respiratory condition $16(4.4 \%)$ and the least prevalent was gastrointestinal conditions $9(2.5 \%)$ (Table 2$)$.

Table 3 shows the prevalence of condition diagnosed in 160 goats presented. The result revealed that endoparasitism had the highest prevalence of $46(28.8 \%)$, followed by viral infections $31(19.4 \%)$, bacterial infections $28(17.5)$, reproductive conditions $16(10 \%)$, ectoparasitism $12(7.5 \%)$, other conditions $9(5.6 \%)$, musculoskeletal disorders 7(4.4\%), gastrointestinal conditions $6(3.8 \%)$ while the least prevalent was respiratory condition $5(3.1 \%)$.

Table 4 gives the summary of cases diagnosed in sheep and goat presented for treatment at State veterinary hospital, Ibadan, Nigeria between July 2013 and June 2018. The total number of cases presented was 520 which include sheep 260(69.2\%) and goats 160(30.2\%). The result further revealed that endoparasitism had the highest 
overall prevalence rate of $163(31.3 \%)$, followed by viral infections 95(18.3\%), bacterial infections 81(15.6\%), reproductive conditions $43(8.3 \%)$, musculoskeletal disorders 40(7.7\%), other conditions 33(6.3\%), ectoparasitism 29(5.6\%), respiratory infection 21(4.0\%) and the least prevalent was gastrointestinal conditions $15(2.9 \%)$.

\section{DISCUSSION}

From this study, it was revealed that cases of sheep were presented for treatment than goat. The probable explanation for this disparity may be due to the hardy nature of goat compare to the sheep. Goats are reported to be more resistant to common diseases than sheep (Peacock, 2006). It could also implies that more people are keeping sheep compare to the goat probably due to its high market value and the socio-religious value especially during Muslim festive period (Aliyu et al., 2005).This finding is similar with the report of Peter et al., (2015) whose study at the state veterinary hospital, Maiduguri, Nigeria recorded more casesof sheep than goats. It also corroborates Unigwe et al., 2016 who had earlier reported that more cases of sheep were presented to Mokola veterinary hospital between July 2009 and June 2013. However, our finding is in contrast with the work of Abiola et al.,(2016) where they reported more cases of goat than sheep at the University of Ibadan veterinary teaching hospital. Meanwhile, our study recorded more cases when compare to the previous work conducted in this location. Unigwe et al.,(2016) had reported that a total of271 small ruminant cases were presented to Mokola veterinary hospital from January 2009 to June 2013. This significant increase in cases presented within similar period of study could be ascribed to the palpable increased sensitization by the government and the professional body of veterinarians through mass media and seminars for the livestock owners. This strategy has been proven to improve livestock production and disease management (Buhari et al., 2015).

The current study also found that endoparasitism is the predominant condition affecting sheep and goat, consistent with what was documented in previous reports (Peter et al., 2015; Abiola et al., 2016; Unigwe et al., 2016), these authors have reported endoparasitism as the most prevalent small ruminants disease in their retrospective studies. The preponderance of helminthosis cases among small ruminant could be traced to the nature of the rearing system in this study location where small ruminants are allowed to roam freely during which they are often exposed to this parasitic agent. This system of rearing coupled with malnutrition makes small ruminants more vulnerable to parasitic infection. Parasitism has been reported as one of the major agents causing serious problem in ruminant in developing countries especially where nutrition and sanitation are poor (Odoi et al., 2008). The second most prevalent disease was viral infections predominantly peste des petit ruminante (PPR) infection. This finding is in agreement with the report of Diallo et al., (2007) that PPR disease is enzootic in several countries of West Africa, contributing to high economic loss in small ruminant production. PPR is highly contagious in nature with case fatality rate of $100 \%$, it is therefore a major concern among small scale livestock keepers who rely on small ruminants as sole source of income (Emikpe \& Akpavie, 2011). It is a vaccine preventable disease and its vaccine is considered to be one of the most effective vaccines ever produced against animal diseases (Diallo et al., 2007). Therefore, the prevalence of this disease in this location could be due to the fact that majority of the animal affected has no previous exposure to PPR immunization. The next most prevalent condition was found to be bacterial infections. This could also be connected to the free range or extensive system of rearing that predominates in this region. It also corroborates the report of Unigwe et al., (2016), that high prevalence of bacterial infection in small ruminants may be due to the exposure of these animals to kitchen waste, decomposed dead animals and grazing on pastures and rangelands littered with various dead animate objects. Reproductive conditions followed bacterial infections in the order prevalence, with dystocia constituting majority of the reproductive conditions recorded in this study. The high occurrence of this condition is attributed to lack of proper monitoring of female animals especially those at reproductive ages, majority of this farmers has no breeding record, as such the animals are bred indiscriminately and often prematurely leading to dystocia. This is in tandem with the report of Abiola et al.,(2016), they reported high prevalence of dystocia as reproductive conditions presented to University of Ibadan veterinary teaching hospital.We also found that musculoskeletal disorder cases were moderately high and trauma (fractures) was the leading cause. This could be easily linked to the fact that small ruminants are often left unguided while they scavenge or graze around, thereby making them more vulnerable to automobile accidents. The least prevalent condition in this study was gastrointestinal conditions such as bloat and other conditions (poisoning, snake bite, malnutrition, conjunctivitis, dog bite, hernia, wound, keratitis, toxicosis and minerals deficiency). This observation is also consistent with the report of Abiola et al., (2016), and this could mean that the owners have been 
managing these cases with usage of ethno-veterinary medicine (Sandabe et al., 2006).

\section{CONCLUSION}

In this study, it is evident that endoparasitism, viral infections, bacterial infections and reproductive conditions are the leading problem ravaging small ruminants. This therefore calls for urgent intervention with special interest towards ensuring proper animal management to control the effect of these agents. It is recommended that veterinary services should be strengthened, accessible and affordable for low income livestock farmers. Mass vaccination against preventable disease like PPR should be routinely done. Livestock farmers should adopt best management practicesthat will minimize the vulnerability of small ruminants to disease. More so, livestock farmers should be sensitized on importance of keeping farm record especially breeding recordin order to mitigate the effect of economic loss associated with these conditions.

\section{ACKNOWLEDGEMENT}

The authors are very appreciative of the unflinching supports rendered by the management of state veterinary hospital, Mokola, Ibadan. We want to specially appreciate Drs Oladipo Bakare, Akibu and Lawal AbdulRazak for their kind assistance.

\section{REFERENCES}

[1] Abiola, O. J., Olaogun, S. C., Emedoh, O. M. \& Jeremiah, O. T. (2016) A Retrospective Study of Ruminant Cases Presented Between 1996 and 2005 at the Veterinary Teaching Hospital, University Of Ibadan, Ibadan, Nigeria. International Journal of Livestock Research, 6 (7), 16-23. doi:10.5455/ijlr.20160706092259.

[2] Ahmed MAA (2010) Gastrointestinal (nematode) infections in small ruminants:Epidemiology, anthelmintic efficacy and the effect of wattle tannins. MSc Thesissubmitted to School of Agricultural Sciences and agribusiness, University of KwaZulu-Natal Pietermaritzburg, pp: 1-6.

[3] Ajala MK, Lamidi OS \& Oturu SM (2008). Per-urban small ruminant production in northern guinea savanna, Nigeria. Asian Journal of Animal and Veterinary Advances, 3(3): 138-146.

[4] Aliyu MM, Bukar MM, Zira AB (2005). Occurrence of smallruminant lameness in Maiduguri and its environs. Sokoto J.Vet. Sci. 6(Supplement): 1-4.

[5] Buhari HU, Saidu SNA, Mohammed G, Raji MA (2015). Knowledge, attitude and practices of pastoralists on bovinebrucellosis in the north senatorial district of Kaduna state. Nigeria. J. Anim. Health Prod. 3(2): 28-34.

[6] Diallo A, Minet C, Le Goff C, Berhe G, Albina E, Libeau $\mathrm{G}$, Barrett $\mathrm{T}$ (2007). The threat of peste des petits ruminants: progress in vaccine development for disease control. Vaccine. 25:5591-5597.

[7] Emikpe, B. O. \& S. O. Akpavie, (2011). Theclinicopathologic effects of Peste des petitsruminants virus infection in West Africandwarf goats. Small Ruminant Research, 95, 168-173.

[8] Lawal-Adebowale OA. (2012). Dynamics of Ruminant Livestock Management in the Context of the Nigerian Agricultural System. In: Livestock Production (Eds. Khalid Javed). Intech. USA. ISBN978-953-51-0814-6. DOI: 10.5772/52923. 61.

[9] MacRae J, O'Reilly L and Morgan P. (2005). Desirable characteristics of animal products from a human health perspective. Livestock Production Science. Vol 94 (1-2): 95-103.

[10] Odoi A, Gathuma MJ, Gachuiri KC, Omore A (2007). Risk factors of gastrointestinal nematode parasite infection in small ruminants kept insmallholder mixed farmers in Kenya. BMC Vet Res. 3: 1-11.

[11] Ogbaje CI, Ajogi I and Ofukwu R. (2012). Diseases and Conditions of Food Animals Mostly Encountered in Zaria Abattoir in Northern Nigeria. Journal of Veterinary Advances. 2(7): 402-406.

[12] Omoike A (2006). Prevalence of disease among sheep and goatsin Edo State, Nigeria. J. Agri. Social Res. 6(2): 23-31.

[13] Peacock C (1996). Improving goat production in the tropics: A manual for development workers. Oxfam. Pp. 265. http:// dx.doi.org/10.3362/9780855987732

[14] Peter ID, Dauda Y, Thlama PB, Ndahi JJ, Madziga HA, Stephen J, Mustapha A (2015). A retrospective study of small ruminant diseases identified at the State Veterinary Hospital Maiduguri, Nigeria. J. Anim. Health Prod. 3(4): 88-93.

[15] Rabiu A, Muhammad A and Mamma S. 2013. Indigenous Treatment Methods of Small Ruminant Livestock in the Tropics -A Case Study from Katsina State, Nigeria. Journal of Agriculture and Veterinary Science, 6(1): 43-46

[16] Sandabe UK, Onyeyili PA and Chibuzo GA. (2006). Phytochemical screening and effect of aqueous extract of Ficussycomorus L. (Moraceae) stem bark on muscular activity in laboratory animals. J. Ethnopharmacol. 104: 283-285.

[17] Singh, B. and Prasad, S. (2008). Modelling of economic losses due to some important diseases in goats in India. Agricultural Economics Research Review, 21:297-302.

[18] Unigwe CR,Ogbu UM,Balogun FA,Orakwue OK,Nwufoh OC and Nwachukwu BC. (2016). Prevalence of Small Ruminant Diseases/Disorders at MokolaVeterinary Hospital, Ibadan, Nigeria. Journal of Biology, Agriculture and Healthcare, 6 (1): 107-112. 
Table 1: Prevalence of small ruminants presented to the StateVeterinary Hospital in Ibadan, Nigeria between July 2013 and June 2018.

\begin{tabular}{lcc}
\hline Species & Number & Prevalence (\%) \\
\hline Sheep & 360 & 69.2 \\
Goat & 160 & 30.8 \\
\hline Total & $\mathbf{5 2 0}$ & $\mathbf{1 0 0}$ \\
\hline
\end{tabular}

Table 2: Prevalence of condition/diseases of sheep presented tothe StateVeterinary Hospital in Ibadan,

Nigeria between July 2013 and June 2018.

\begin{tabular}{lcc}
\hline Diseases & Number of cases & Prevalence (\%) \\
\hline Bacterial & 53 & 14.7 \\
Viral & 64 & 17.8 \\
Endoparasitism & 117 & 32.5 \\
Ectoparasitism & 17 & 4.12 \\
Reproductive & 27 & 7.5 \\
Gastrointestinal & 9 & 2.5 \\
Respiratory & 16 & 4.4 \\
\hline
\end{tabular}

\begin{tabular}{lcc}
\hline Musculoskeletal & 33 & 9.2 \\
Others & 24 & 6.7 \\
\hline Total & $\mathbf{3 6 0}$ & $\mathbf{1 0 0}$ \\
\hline
\end{tabular}

Table 3: Prevalence of condition/diseases of goat presented tothe State Veterinary Hospital in Ibadan, Nigeria between July 2013 and June 2018.

\begin{tabular}{lcc}
\hline Diseases & $\begin{array}{c}\text { Number of } \\
\text { cases }\end{array}$ & Prevalence (\%) \\
\hline Bacterial & 28 & 17.5 \\
Viral & 31 & 19.4 \\
Endoparasitism & 46 & 28.8 \\
Ectoparasitism & 12 & 7.5 \\
Reproductive & 16 & 10 \\
Gastrointestinal & 6 & 3.8 \\
Respiratory & 5 & 3.1 \\
Musculoskeletal & 7 & 4.4 \\
Others & 9 & 5.6 \\
\hline Total & $\mathbf{1 6 0}$ & $\mathbf{1 0 0}$ \\
\hline
\end{tabular}

Table 4: Summary of prevalence of condition/diseases of sheep and goat presented tothe StateVeterinary Hospital in Ibadan, Nigeria between July 2013 and June 2018.

\begin{tabular}{lccc}
\hline Diseases & Sheep $(\boldsymbol{\%})$ & Goat $(\boldsymbol{\%})$ & Total $(\boldsymbol{\%})$ \\
\hline Bacterial & $53(10.2)$ & $28(5.4)$ & $81(15.6)$ \\
Viral & $64(12.3)$ & $31(5.96)$ & $95(18.3)$ \\
Endoparasitism & $117(22.5)$ & $46(8.8)$ & $163(31.3)$ \\
Ectoparasitism & $17(3.3)$ & $12(2.3)$ & $29(5.6)$ \\
Reproductive & $27(5.2)$ & $16(3.1)$ & $43(8.3)$ \\
Gastrointestinal & $9(1.7)$ & $6(1.2)$ & $15(2.9)$ \\
Respiratory & $16(3.1)$ & $5(0.96)$ & $21(4.0)$ \\
Musculoskeletal & $33(6.3)$ & $7(1.3)$ & $40(7.7)$ \\
Others & $24(4.6)$ & $9(1.7)$ & $33(6.3)$ \\
\hline Total & $\mathbf{3 6 0}(\mathbf{6 9 . 2})$ & $\mathbf{1 6 0}(\mathbf{3 0 . 8})$ & $\mathbf{5 2 0}(\mathbf{1 0 0})$ \\
\hline
\end{tabular}

